\title{
Comparison of Pregabalin and Agmatine Effects on Experimental Neuropathic Pain in Mice
}

\author{
Ceren Aygün Muçuoğlư ${ }^{1}$, Ayşe Karcı ${ }^{1}$, Gül İnal' ${ }^{1}$, Ceren Kızmazoğlu², Ali Osman Muçuoğlu
}

${ }^{1}$ Dokuz Eylul University Faculty of Medicine, Department of Anesthesiology and Reanimation İzmir, Turkey

2Dokuz Eylul University Faculty of Medicine, Department of Neurosurgey İzmir, Turkey

\section{Background}

In addition to primary analgesic agents various adjuvant agents have been used in treatment of neuropathic pain. Evidence has been gathered that drugs affecting the NMDA receptors play an important role in treatment of chronic pain. The aim of this study was to investigate the anti-nociceptive effects of agmatine and compare these effects with pregabalin in a chronic pain model.

\section{Material and Method}

The neuropathic pain was induced by partial ligation of right sciatic nerve (PSL) in Balb/c mice under general anesthesia. The study was performed on six groups of mice including 7 animals in each one. The animals were grouped as follows: Group 1 Control $(n=7)$, Group 2 Sham ( $n=7)$, Group 3 Neuropathy (PSL, $\mathrm{n}=7$ ), Group 4 Neuropathy (PSL, $50 \mathrm{mg} / \mathrm{kg}$ pregabalin, $\mathrm{n}=7$ ), Group 5 Neuropathy (PSL, 50mg/kg agmatine, n=7), Group 6 Neuropathy (PSL, $50 \mathrm{mg} / \mathrm{kg}$ pregabalin $\& 50 \mathrm{mg} / \mathrm{kg}$ agmatine, $\mathrm{n}=7$ ). The baseline measurements of hot plate latency (HPL) and acetone evaporation tests were performed on the 14. postsurgical day and the results were recorded. The study drugs were injected intraperitoneally (i.p) during the following 14 days to groups 4,5 and 6 th. At the end of the 28th day the tests were repeated in all groups.
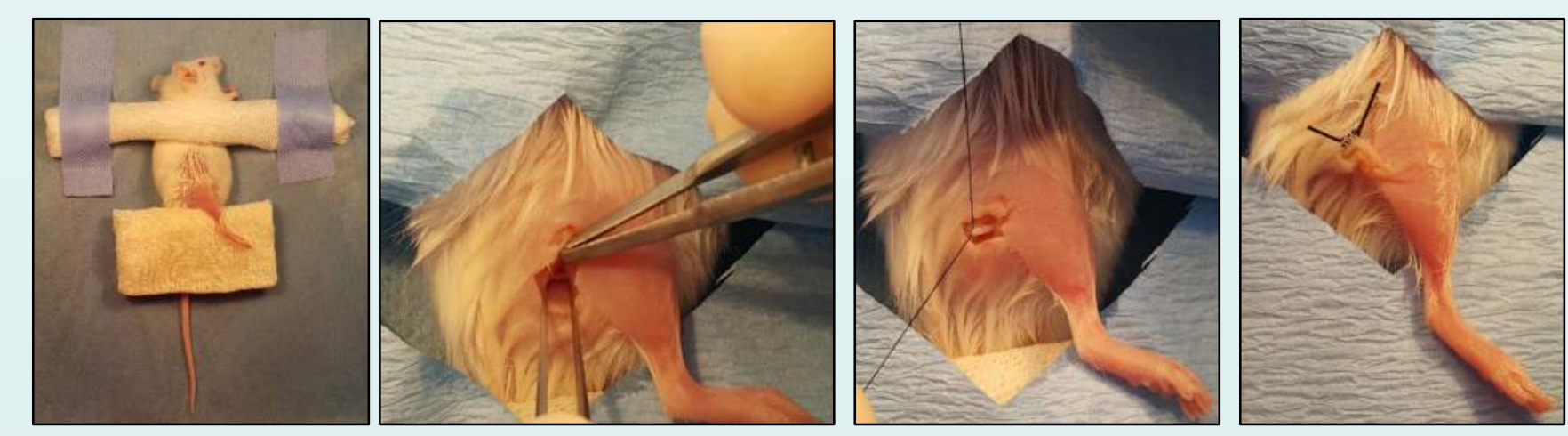

\section{Results}

The significant difference between groups in baseline values for the HPL test showed the presence of neuropathic pain in mice who had sciatic nerve ligation $(p<0.05)$. The HPL values were similar in control and sham groups; highest values were obtained in the control group and the lowest ones were in the agmatine group.

\section{References}

1. Kotagale N.R., Shirbhate S.H. et al. Eur J Pharmacol 2013;714(1):424-431

2. Aricioglu F., Korcegez E. et al. Ann NY Acad Sci 2003;1009(1):106-115

Sezer A., Güçlü B. et al. Turkish Neurosurgery 2014;24(2):196-201

Yang X.C. and Reis D.J. J Pharmacol Exp Ther 1999;288(2):544-549
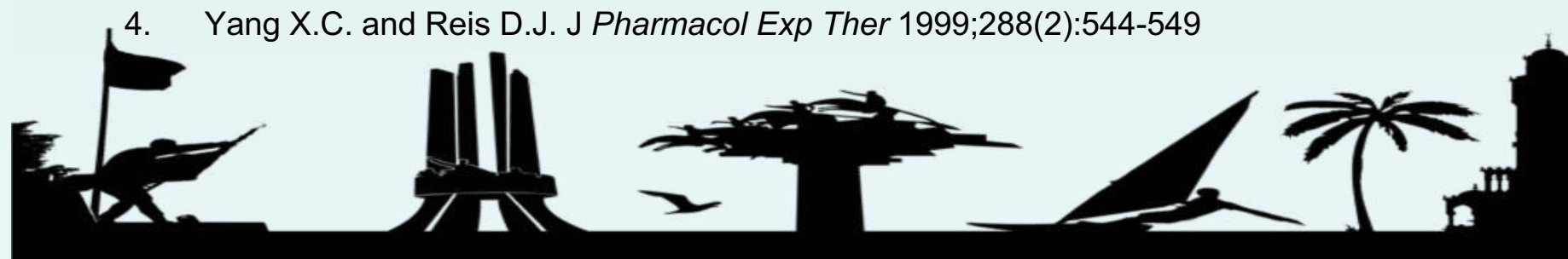

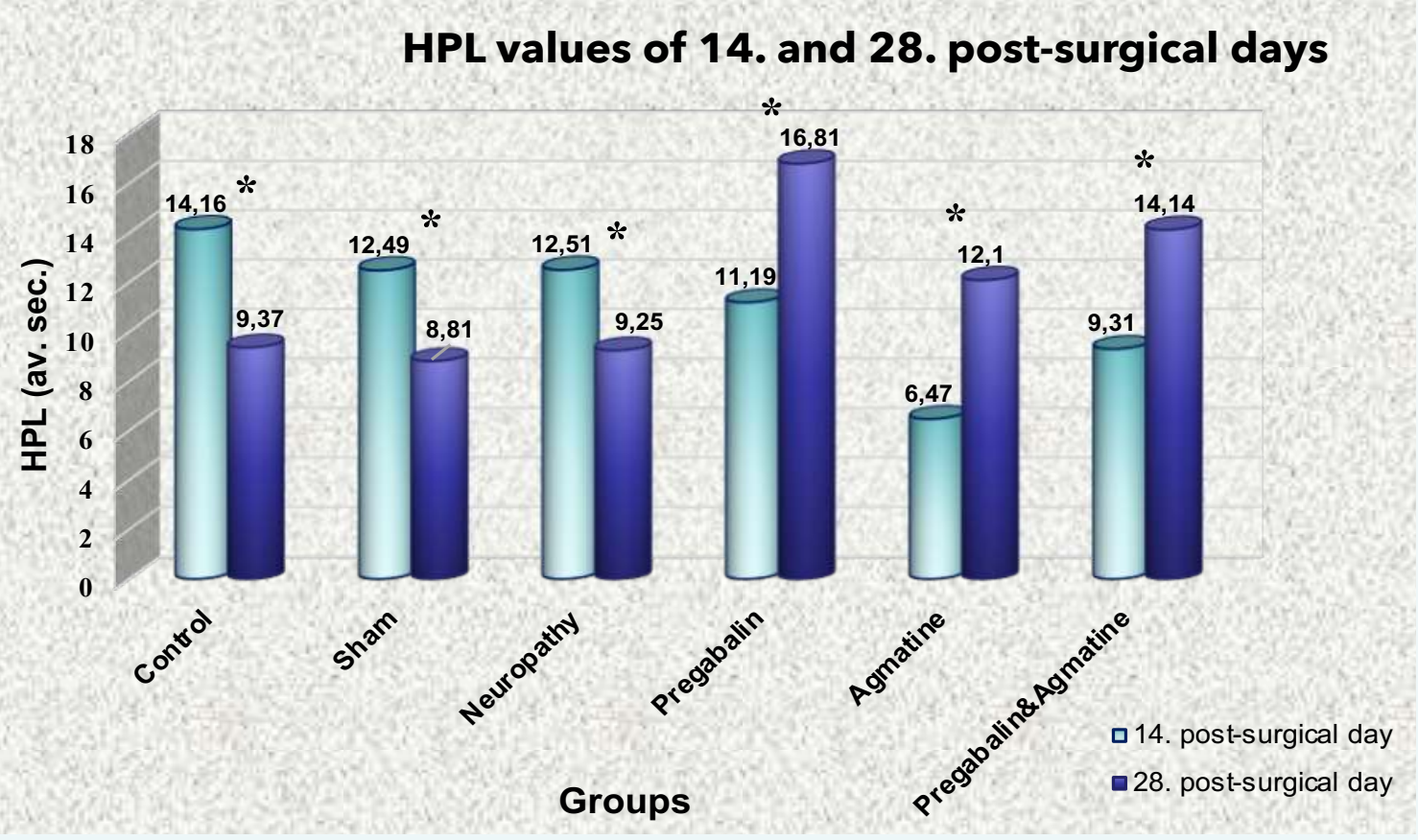

The results were similar between the other groups. On the 28th day the difference in the HPL results were not statistically significant $(p>0,05)$. The difference between the two measurements were found to be statistically significant in all groups $(p<0,05)$. Comparison of the baseline acetone evaporation percentage and its measurement on the 28th day showed a significant difference $(p<0,05)$. The test results of the control group were lower compared to the groups with neuropathy. The results did not differ in groups receiving the study drugs. The difference of the baseline and 28th day measurement of acetone evaporation test were only significant in the agmatine and pregabalin \& agmatine groups $(p<0,05)$.

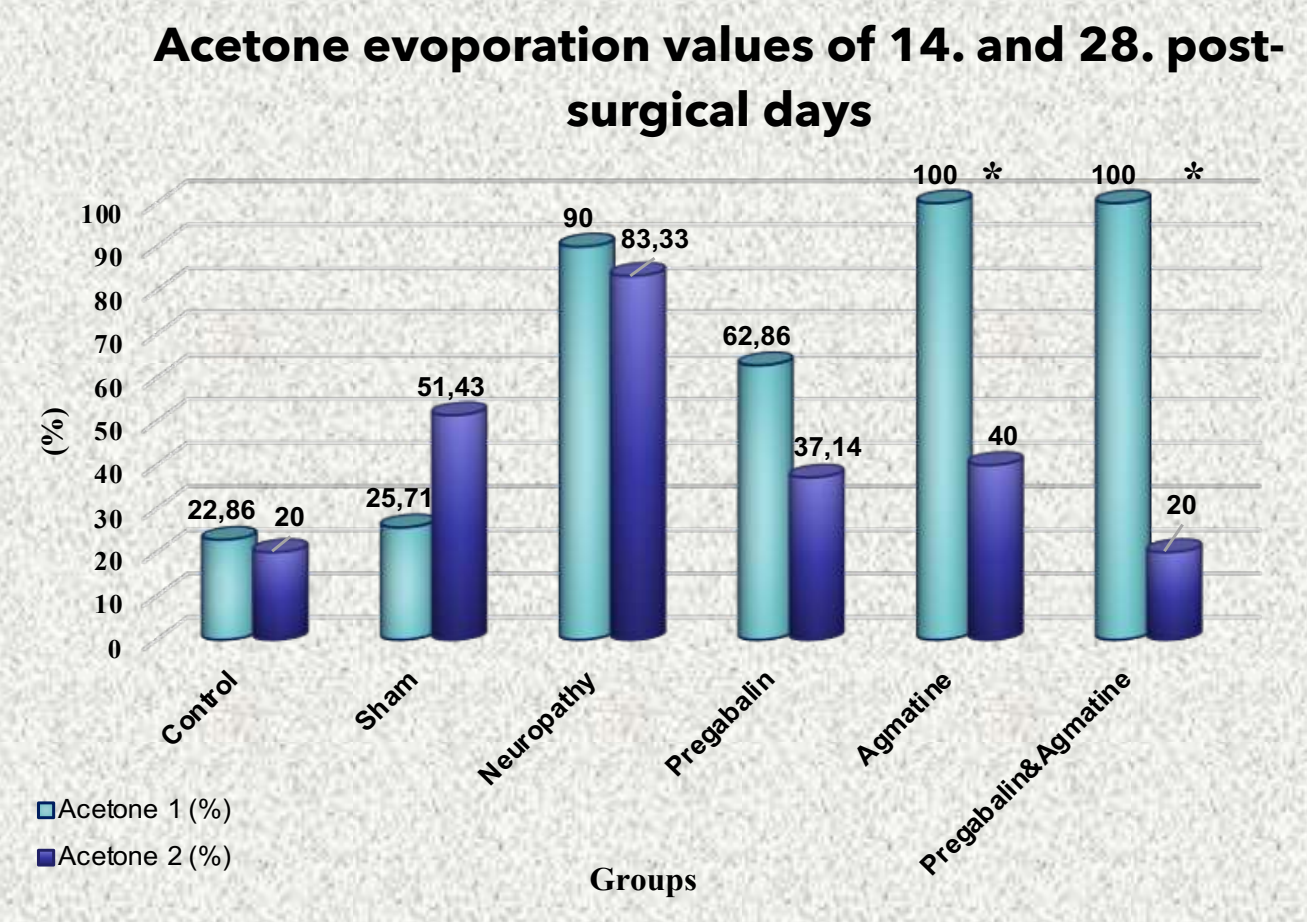

\section{Conclusion}

Our results have shown that agmatine a NMDA receptor antagonist has remarkable antinociceptive effects in neuropathic pain and this effect is comparable to pregabalin. Addition of agmatine to treatment in neuropathic pain was more effective in relieving allodynia symptoms compared to administering only pregabalin.

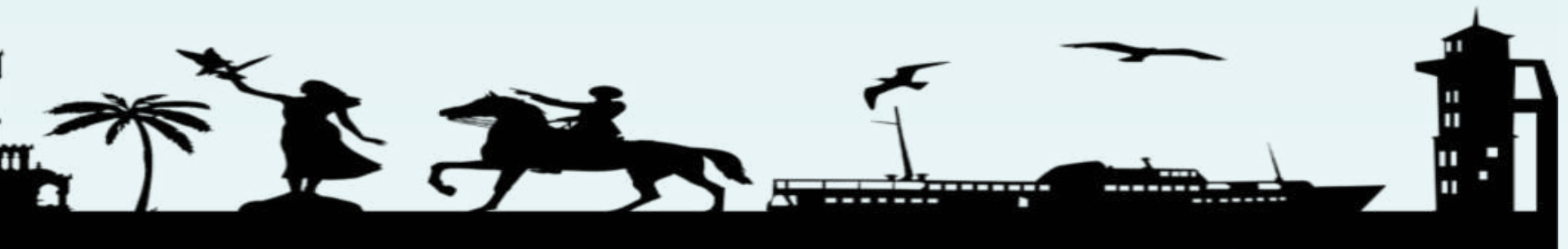

